\title{
Operating principles for collective scholar-activism: Early insights from the Agroecology Research-Action Collective
}

\author{
Maywa Montenegro de Wit ${ }^{a}$ * \\ University of California Santa Cruz
}

Annie Shattuck ${ }^{b}$

University of Indiana, Bloomington

Alastair Iles ${ }^{c}$

University of California, Berkeley

\author{
Garrett Graddy-Lovelace ${ }^{\mathrm{d}}$ \\ American University
}

Antonio Roman-Alcalá ${ }^{\mathrm{a}}$

International Institute for Social Studies

\author{
M. Jahi Chappell ${ }^{\mathrm{f}}$ \\ Southeastern African American Farmers' \\ Organic Network (SAAFON)
}

Submitted May 23, 2020 / Revised August 12, October 7, and October 15, 2020 / Accepted October 16, 2020 /

Published online February 11, 2021

Citation: Montenegro de Wit, M., Shattuck, A., Iles, A., Graddy-Lovelace, G., Roman-Alcalá, A., \& Chappell, M. J. (2021). Operating principles for collective scholar-activism: Early insights from the Agroecology Research-Action Collective. Journal of Agriculture, Food Systems, and Community Development, 10(2), 319-337. https://doi.org/10.5304/jafscd.2021.102.022

Copyright (C) 2021 by the Authors. Published by the Lyson Center for Civic Agriculture and Food Systems. Open access under CC-BY license.
Abstract
Scholar-activism is attractive to researchers who want not just to learn about the world, but about how to change that world. Agri-food studies have experienced a surge in the past two decades in researchers who see closer ties to social move- ments as key to food systems change. Yet to date,
a * Corresponding author: At the time of the research, Dr. Maywa Montenegro de Wit was University of California President's Postdoctoral Fellow, Department of Human Ecology, University of California, Davis.
Dr. Montenegro de Wit is now Assistant Professor, Department of Environmental Studies, University of California Santa Cruz; 1156 High Street; Santa Cruz, CA 95064 USA; mamonten@ucsc.edu
b Annie Shattuck, Assistant Professor, Department of Geography, University of Indiana, Bloomington; shattuck@iu.edu
c Alastair Iles, Associate Professor, Department of Environmental Science, Policy, and Management, University of California, Berkeley; iles@,berkeley.edu
much scholar-activism depends on individually negotiated researcher-movement relationships, which may or may not be sustained long term and where knowledge can remain siloed. The Agro- ecology Research-Action Collective (ARC) seeks something different. Born of a desire to subordi- nate scholarship for scholarship's sake to the needs and exigencies of movements, ARC envisages collective processes, horizontal non-exploitative learning among ourselves and with movements, and mechanisms for multidirectional accounta- bility. This reflective essay is the story of how ARC
d Garrett Graddy-Lovelace, Associate Professor, School of International Service, American University; graddy@american.edu
e Antonio Roman-Alcalá, International Institute for Social Studies, The Hague, Netherlands; antidogmatist@gmail.com
${ }^{\mathrm{f}}$ M. Jahi Chappell, Executive Director, Southeastern African American Farmers' Organic Network (SAAFON); mjchappell@saafon.org 
set out to "get our house in order": to organize ourselves as scholars committed to systematizing more accountable and reciprocal relationships with frontline communities and grassroots movements. We first share the Principles \& Protocols that guide our actions and the process through which we developed them. We then discuss two interconnected arenas in which ARC is developing a community of practice guided by the Principles \& Protocols. The first arena is through integrating participatory education into our everyday teaching and mentoring. The second arena is working to achieve broader social and institutional change by sharing methods and strategies for mobilizing resources and legitimating knowledge, both old and new.

\section{Keywords}

Scholar-Activism, Agroecology, Participatory Action Research, Community-Based Research, Food Systems, Food Sovereignty

\section{Introduction}

The public's rising interest in sustainable food and agriculture over the past two decades has dovetailed with multiple interconnected crises - in climate, biodiversity, human health, and democracy, among others-leading many scholars to say they want to make a difference. A wide array of social scientists in North America asking the knotty question "What will it take to transform food systems?" have arrived at the answer: in collaboration with frontline communities and organizations. ${ }^{1}$ The resultant surge in research has opened up space to delve into root-cause dilemmas: asking what dismantling racism in the food system looks like, exploring how to transform an industry that employs a third of people on the planet, and identifying where to begin intervening in agri-food systems that contribute to diet-related disease epidemics, emit up to a third of greenhouse gas emissions, and produce tremendous yields but fail to nourish people equitably.

Yet, as scholars participating in these dia- logues, we worry that such scholarship may miss the mark in terms of advancing social change. We have had countless conversations with community organizers, activists, and farmers, both urban and rural, who share stories of feeling used or burned by both researchers and the universities under whose auspices those researchers work. As a result, skepticism pervades in the communities we imagine we are serving, collaborating with, or trying to understand. This tension is nothing new, as scholar-activists have been openly discussing such challenges for decades (Borras, 2016; Hale, 2008; Hall \& Kidd, 1978). Precisely because this type of work has been poorly understood or executed in the past-whether by neglecting to share the fruits of research or failing to listen to collaborators' needs from the start—scholar-activists fail to gain traction on "making a difference."

Responding in part to this deficit, over the past decade, memoranda of understanding (MOUs) produced in partnership between scholars and research partners have become more sophisticated and radical, outlining guideposts for a mutually beneficial researcher-community partnerships (e.g., Superstorm Research \& Disaster Collaboratory, Healthy African American Families, Karuk-UC Initiative, Civic Laboratory for Environmental Action Research Lab). Calls for data sovereignty (community members' control over data they provide to researchers) have become more pronounced, especially from Indigenous scholars and organizations (Hudson et al., 2020). Some of these protocols have even been institutionalized into review boards and university standards (such as at Memorial University, Newfoundland, and University of Victoria, B.C.). However, institutional recognition is not the norm; with a few notable exceptions (e.g., the Karuk-UC Initiative), the deep decolonizing work represented by tribal MOUs mostly exists as independent initiatives and agreements between individual researchers or projects and their partner organizations. MOUs may or may not extend to a wider network of scholar-activists

\footnotetext{
${ }^{1}$ Frontline communities are those that most directly experience the adverse impacts of environmental and social injustice. Frontline movements, in turn, refer to organized communities fighting against dangerous work conditions, toxic living environments, and systematic oppression. In the food arena, examples of such groups in the U.S. include the Rural Coalition, Community to Community, and the Federation of Southern Cooperatives.
} 
or have a shelf life beyond the length of the project.

This gap between the desire for engaged, effective, accountable research and its successful and sustained execution led us to develop the Agroecology Research-Action Collective (ARC) in 2017. ARC is a group of roughly 50 scholar-activists ${ }^{2}$ who focus on issues of farm justice, food justice, food sovereignty, and agroecology in the North American context. Roughly $85-90 \%$ of us identify as social scientists, but we represent a range of biophysical and social science disciplines, including soil science, horticulture, ecology, geography, agroecology, sociology, anthropology, science and technology studies, international relations, and public policy. Our scholarship is also not confined to the academy: We work in universities, community colleges, nonprofits, and independent positions. Many of us engage in community-based or activist work of one sort or another, including with farmers' organizations, farmworkers, small nonprofits, and activist groups. For some of us, this activity has been central to our personal and political lives. For others, it has been central to our professional careers. For many of us, it is both. While we share the mission of advancing agroecology in North America, for many of us, scholar-activism was_-and remains_-ignited by social movements abroad.

Early on in the formation of ARC, we were challenged by long-time food sovereignty organizers to "get your house in order"- - to organize ourselves as scholars committed to systematizing more accountable, reciprocal relationships between researchers and the communities with whom we work. This call to action from grassroots allies was less about asking scholars to get more involved with frontline organizing than it was about asking us to look internally at our institutions and think deeply about our ethical commitments. It also reflected an important current trend in U.S. and international agroecology: Many individual scholars have dedicated themselves and their research to working in and with movements to advance food system transformations. Yet, not enough analysis has been done to address the issue of how to foster alliances or coalitions between scholar-activists and other actors in movements for agroecology, food sovereignty, and agrarian justice (Duncan et al., 2019). This is the work ARC set out to do. We wanted to bring together a cohort of scholaractivists and begin building "formal operating mechanisms" for ourselves that move beyond individually negotiated researcher-movement relationships to envisage collective processes, horizontal non-extractive learning, and mechanisms for accountability. Adopting and adapting operating mechanisms can help scholars overcome the gap between their desire to do research with a practical impact on social change and pervasive obstacles to such work.

In this reflective essay, we discuss a set of Principles \& Protocols we have developed for this purpose. Designed to be simple and easy to circulate, they are something frontline groups can use to negotiate with researchers and that researchers can use to co-design transformative research with frontline organizations. We first outline the early organizing efforts and movement feedback through which we arrived at the idea of ARC, an autonomous organization of scholar-activists. Next, we sketch the collaborative process leading to the development of the Principles \& Protocols. Finally, we discuss (1) teaching and mentoring and (2) institutional change as two areas in which activist-scholars can make it easier to reconcile their professional demands with their commitments to support frontline groups. ${ }^{3}$

\footnotetext{
${ }^{2}$ For the purposes of linguistic diversity, we use "scientist," "researcher," "scholar," and "academic" as loosely interchangeable terms in this text. We want to underline, however, that of course not all scholars exist within the academy; a number of ARC members work in civil society organizations or independently. Similarly, research and scholarship can be done by grassroots organizations and community actors; trained professionals certainly do not own this domain of practice. Though we use "scholarship" to primarily refer to formal science or research, we do not wish to restrict that term: ARC's goal is that "scholarship" will be produced in relation between academics and/or scientists and social movement knowledge-makers.

${ }^{3}$ Our article represents the experience and perspectives of the authors (as coordinating committee members and co-founders of ARC) and not ARC as an organization. We share what we have developed not to say that it is the most "correct" approach, but to offer our experience as a way of building shared knowledge about research that is more accountable, more reflexive, and more directly in
} 


\section{Accountability and Reciprocity: Doing Research Differently}

Though scholar and activist identities have been marbled since at least the time of the ancient Greeks (Calhoun, 2008), and, in non-Western traditions, through cultures of Maya, Aymara, Quechua, and other Indigenous thinker-doers, the recent burst of scholar-activism in food systems research is noteworthy. Over the past five years, several workshops, articles, and special issues have been dedicated to documenting the struggle to do accountable food justice research (Croog, HayesConroy, \& Guttierez-Velez, 2018; Orozco, Ward, \& Graddy-Lovelace, 2018; Herrera, 2018; Levkoe et al., 2016; Reynolds, Block, \& Bradley, 2018). Conventional research practices, this scholarship suggests, often lack transparency or a means for research protagonists to shape research questions, methods, or how the "subjects" are represented, thus reproducing what some scholars have named an extractive colonial research dynamic (Bradley \& Herrera, 2016). Even self-consciously "inclusive" research, where research questions come from the community and their active participation is prioritized, can retrench colonial habits. "Inclusion is a form of diversification but it can also be violent," notes the Civic Laboratory for Environmental Action Research (CLEAR), explaining that "inviting voices into spaces not built for them or that undermine their messages, lived experiences, and expertise can often work against the well-intentioned goals of inclusion" (CLEAR, 2018, "Decolonizing your syllabus?" para. 2; see also Tuck \& Yang, 2012).

These dynamics can impede both good scholarship and social change. Becoming an expert in new political developments in social movements, frontline communities, or some aspect of what Gilmore calls "the politically and oppositionally new” (Gilmore, 1993, p. 71) can advance one's academic career. Yet the prevailing university institutional culture creates pressures for pursuing individualistic research that is often disarticulated from larger struggles for change (Gilmore, 1993). Researchers' disciplinary skills and the needs of partner organizations are often mismatched; communities may not know what they want out of a research process; and defining "the community" in community-based research can be empirically, politically, and personally challenging (Pulido, 2008). Movement groups also express concerns about university teams obtaining funding that would otherwise go to frontline organizations, ${ }^{4}$ teams not sharing "participatory" grant funding, and grassroots organizations simply not having enough resources to participate in research, even when that research is beneficial to them.

Different approaches to resolving these tensions, in turn, have generated lively debates within scholar-activism. For example, productive frictions exist between schools that view the "production and mobilization of knowledge" as the primary task for scholar-activists (e.g. Calhoun, 2008) and those who see the principal role for such scholars as resource agents, channeling capital, access to privileged spaces, and information towards social movement needs (e.g., Derrickson \& Routledge, 2015). Some theorists understand scholar-activists as integrated in movements, such that movements' knowledge becomes imbricated in their own knowledge production (Brem-Wilson, 2014). Others argue in favor of complementarity: "an autonomous, two-way, mutually reinforcing interactive approach that recognizes the ability of both peasants and scholar-activists to generate knowledge (Borras, 2016)" (Duncan et al., 2019, p. 6).

In recent years, researchers have also explored the particular challenges of how to relate scholaractivism to food movements. For instance, Duncan et al. (2019) discuss the place of researchers in the larger European food sovereignty movement and whether they can form their own constituency within the movement's governance architecture. In Europe, activist-scholars in this arena tend to focus on their individual research agendas and are primarily accountable to their home institutions, even

service of food systems transformation.

4 Although major science funders (National Science Foundation, U.S. Department of Agriculture, U.S. Department of Energy, National Institutes of Health) generally do not hold competitions for which frontline organizations are eligible, there is direct competition when it comes to foundation dollars. 
though they seek to collaborate with and be more accountable to movements. As a result, they have a fragmented identity and struggle with issues such as a lack of collective organization, the inability to formulate a shared position, and a weak recognition by movements of their contributions as supporters of food sovereignty. Simultaneously, activist-scholars worry about overshadowing movement knowledge and leadership through asserting their expertise. Responding to these tensions, Duncan et al. (2019) call for the creation of "formal operating mechanisms" that can help researchers move beyond individually negotiated researcher-movement relationships and towards collective processes that require and reproduce non-hierarchical and mutually beneficial relationships rather than extractive and oppressive ones. This is the challenge to which ARC's collective development of Principles \& Protocols responds.

While reflecting these debates in food scholaractivism, ARC also carries forward old traditions in agroecology in which researchers insert themselves into grassroots political and social struggles as activist-scholars (Fals-Borda \& Rahman, 1991; Rappaport, 2008). Orlando Fals-Borda, the intellectual forebearer of participatory action research (PAR), honed his thinking through working with campesinos within the Colombian Ministry of Agriculture in the late 1950s (Wakeford \& Sanchez Rodriguez, 2018). Drawing on Freirean approaches to transformative adult education, Fals-Borda coorganized the first international meeting of participatory action researchers in 1978, crafting a list of principles upon which a majority of further actionresearch approaches, including ours, draw heavily (Hall \& Kidd, 1978; Wakeford \& Sanchez Rodriguez, 2018). These principles then informed social process methodologies using on-farm action research and cycles of participatory analysis and reflection that were key to the spread of agroecology across Latin America in the 1980s and 1990s (Holt-Giménez, 2006).

Inspired by these early PAR efforts, contemporary agroecology combines scientific methods, on-farm practices, and social movement organization (International Planning Committee for Food Sovereignty, 2015; Méndez, Bacon, Cohen, \& Gliessman, 2015; Vandermeer \& Perfecto, 2013).
Though it bears emphasizing that there is no singular "agroecology," the trend in the past decade has been towards deepening the explicit entanglement of the natural and social sciences and defining a politics of systemic transformation (Anderson, Bruil, Chappell, Kiss, \& Pimbert, 2019; de Molina, Petersen, Peña, \& Capor, 2019; Rosset \& Altieri, 2017). This trend includes, for example, recognizing that the struggle over ideas, meaning, and narratives in agroecology has very real implications for the material struggles to advance a more just and sustainable food system (Giraldo \& Rosset, 2017). It means multiple lines of research into the key drivers of bringing agroecology "to scale" (Brescia, 2017; Mier y Terán et al., 2018), with emphasis on the roles of crises, social organization, training and education, effective agroecology practices, favorable markets and policies, and external allies. It means interrogating how such external allies have been critical to agroecology movements in documented cases around the world: from pivotal NGO support for the Campesino a Campesino movement in Central America (Holt Giménez, 2006) to the controversial Hindu Ashrams backing the Zero Budget Natural Farming movement in India. "Academics," many accounts suggest, are linchpins in agroecology's success (Gliessman, 2017; Mier y Terán Giménez Cacho et al., 2018; van den Berg, Kieft, \& Meekma, 2017). But, to our knowledge, the agroecology literature has not directly addressed how to foster such alliances or coalitions between scholaractivists and other actors in the movement.

\section{ARC Origins: Getting Our House in Order} In 2014, the UN Food and Agriculture Organization (FAO) convened the First International FAO Agroecology Symposium, followed by several regionally specific agroecology conferences around the world. But North America was not included in these regional dialogues, largely due to a lack of organized presence for agroecology on the continent. A group of academics, who were loosely affiliated with each other through shared agroecology interests, set out to assemble a multistakeholder alliance across research, education, and advocacy sectors to fill this gap. We sketched plans about what we wanted to do, beginning with a mission statement for outreach to groups whom we hoped 
would join our envisioned large and wide-ranging initiative, which we dubbed the North American Agroecology Forum. Even the earliest activity, however, underlined for us the paradox of advancing a project which we expected would be of value-but movements may not agree. Toward understanding if, where, and which grassroots groups would be interested in this forum, we recognized the need to involve movement stakeholders at the earliest stages of the decision-making process. But we quickly found that even drafting something as apparently simple as an invitation statement assumed certain ideas about who gets to define "what agroecology is." Making such decisions required more diverse participation, which we sought out - with surprising results. In spring 2016, representatives of several grassroots and civil society organizations, including the National Family Farm Coalition, Rural Coalition, the Institute for Agriculture and Trade Policy, WhyHunger, Pesticide Action Network North America, Food First, and La Vía Campesina, came together to discuss our nascent effort, and gave us a wake-up call with the following list of concerns:

- Would the North American Agroecology forum be willing and able to work with frontline groups to co-develop ethical and accountable principles and terms of engagement?

- How would the forum synchronize with existing groups and group processes? Would it destabilize or displace them?

- Would forum members be willing to go to the spaces where movements are already living and working?

- To what extent would the forum be available to support the urgent survival and policy priorities of frontline groups?

Grappling with our own responses to these questions, we held a series of further meetings with frontline groups. Taken together, their advice was that we abandon the effort to build a large, multisectoral coalition. We had to get "our house" in order by being much more reflexive about what we academics were doing. We had to organize as researchers and scholars inside the institutions we know and within which we work. We had to figure out how we will dialogue with communities in ways that are not just "responsible" but that empower communities as coequal partners in producing knowledge about food systems and how to change them. Scholar-activists, we understood, always exist on both sides of the university-community equation; to borrow from the scholar Antonio Gramsci, we in fact represented the "traditional intellectuals" in positions of privilege while we pursued counterhegemonic work in undoing hierarchies of privilege, knowledge, and power. How many of us were willing to commit "class suicide" (Cabral, 1966)? How could we join with communities' many organic intellectuals without reconstituting hierarchies or undermining their expertise?

As part of working through these questions, the authors cofounded ARC in April 2017, as a group of scholar-activists who were willing to commit to this process and to take seriously the challenges of partnering with social movements on an equal footing. We circulated an invitation that spring and about 20 people initially joined. Over the next year, ARC built its decision-making procedures, membership, and working groups, with a coordination committee (including the authors) providing the administrative support required for ARC to function as a collective. We began holding monthly ARC-wide calls where core members collectively make decisions about projects, and when needed, take online votes to assure that all ARC members can participate. Generally, ARC operates on a consensus principle. In November 2019, ARC held its first-ever constituent assembly to define strategic directions and enrich community-building; by then we had grown to roughly 50 members, with 20-30 members participating very consistently and actively, including at the assembly.

ARC differs from the efforts reported in Duncan et al. (2019) in that we are consciously creating a network of activist-scholars who all work on agroecology and food sovereignty, across multiple institutions and organizations, some universitybased, some independent, some NGO-based. To name a few examples, one of us specializes in community-based approaches to advancing agroecology for food security, nutrition, and gender justice in Malawi (Bezner Kerr, Hickey, Lupafya, \& 
Dakishoni, 2019). Another of us focuses on food movement organizing in U.S. cities, with an eye to mass incarceration and racial stratification (Sbicca, 2018). Several of us work on farmworker rights, agrarian justice, and social change effected through grassroots organizing (Graddy-Lovelace, 2017; Madrigal, 2015), in transnational politics (Shattuck, Schiavoni, \& VanGelder, 2018), and via storytelling (Montenegro de Wit, 2014; Wills \& Sampson, 2018), while several others have long-running research programs on agroecology, food sovereignty, and sustainable food systems in Canada, the U.S., and Latin America (Anderson, 2013; Iles, Graddy-Lovelace, Montenegro de Wit, \& Galt, 2016; Mendez, Bacon, \& Cohen, 2015; Patel, 2009; Wittman \& Blesh, 2010). A good many of us in civil society work to expand the purchase of agroecology (and counter the power of agribusiness) in U.S. and international policy contexts (Chappell, 2019; Ferguson, 2019; Ishii-Eiteman, 2019; Varghese, 2020). And another cohort is advancing agroecological learning: how collective learning and cooperation occurs, where theory and practice most efficaciously entangle, how land and territories can be regenerated through working knowledge and transformative to education for solidarity and care (Anderson, Maughan, \& Pimbert, 2018; Tarlau, 2019; Meek, 2020). We realized that there was a catalytic potential in organizing our scholarship together.

To date, ARC has created a community of shared knowledge and practice centered on monthly online meetings and, pre-COVID-19, travel to participate in movement-led spaces. Working groups have undertaken specific projects, such as Green New Deal policy recommendations in support of agroecology and food sovereignty, ${ }^{5}$ and organized scientific reviews of FAO agroecology reports. ${ }^{6}$ Learning with and from grassroots organizations motivates the work many of us do as educators, as we discuss further below. We also learn from each other, transmitting know-how on participatory research and education from the more seasoned scholar-activists to those of us with less skill and experience in this area. This creates a community of shared practice that is essential to "scaling" agroecology within — and beyond-the institutions whose resources can be brought to support frontline practitioner communities. Between 2017 and 2020 we have grown in many ways, moving from aspirations for conference planning to ongoing engagements with the U.S. Food Sovereignty Alliance, the People's Agroecology Process, and other grassroots organizations. Getting to this point was facilitated, in large part, by having developed Principles \& Protocols that reflect the horizontal, reciprocal relationships that can lead to better, more accountable knowledge production.

\section{Making the Principles \& Protocols}

Recognizing that diverse communities of practice have developed guidelines for community-based research, in 2017 we began by surveying existing literature and memoranda of understanding. Some texts we drew inspiration from included "Practicing Pikyav" (Karuk-UC Berkeley Collaborative, n.d.), a policy which UC Berkeley researchers codeveloped with the Karuk people in northern California to guide collaborative projects in areas from water access to food security. Using a codesigned protocol, the Food Dignity project (Porter, 2018) worked over seven years with community-based organizations that provide food aid to study how those groups invest in building solidarity networks. The STEPS Centre's Practicing Ethical Activist Scholarship for Sustainability Transformations framework (Gwiszcz, 2016) was formulated between scholars at the University of Sussex and three community-based networks working on environmental justice, learning for sustainability, and socio-ecological policy. We also drew on a termsof-engagement memo between the farm bill practicum class at American University and frontline organizations (which we discuss further below).

We assembled these texts, organized themes conceptually, and highlighted elements specific to agroecology research and practice. This first draft was then shared with coordinators at several organizations with whom we had existing connections-

\footnotetext{
${ }^{5}$ https:/ / agroecologyresearchaction.org/green-new-deal/

${ }^{6}$ https:/ / agroecologyresearchaction.org/response-to-hlpe-draft-report/
} 
the HEAL Food Alliance, the National Family Farm Coalition, the U.S. Food Sovereignty Alliance, the Community Alliance for Agroecology, and the Pesticide Action Network North America-with a request for comments. Specifically, we needed feedback on what was helpful? What was missing? Which elements could be changed and how? We also workshopped the principles internally.

Formally adopted by ARC in September 2017, the collectively agreed upon Principles \& Protocols (ARC, 2019) below are intended to provide guidelines for participation as researchers in ARC. These principles are not intended to be comprehensive or definitive. They certainly do not represent a comprehensive distillation of PAR, decolonial, feminist, and other engaged approaches. Nor are they novel in activist-scholar practice. They do represent a preliminary list of things that we and our community collaborators find useful in the beginning of a process of creating research that lives up to the demand for accountability, reciprocity, humility, and solidarity. We put them forward in hopes that a short list will be of practical use, that these principles will be refined, debated and improved, and ultimately help change research practice.

\section{- Principles of collaborative research development}

1. Research questions should, from the earliest stage, emerge from a process of dialogue between researcher(s) and community and/or movement partners.

2. The process of research after definition of research questions must involve ongoing collaboration in all steps, such as research design, implementation, data collection, and so on.

3. These guidelines themselves are subject to continual development in dialogue with community and movement partners - at this stage, they exist as a baseline to work from and will evolve as the group evolves.

4. This also goes for individual projects: ARC members will review and revise this list with community and/or movement partners in new research efforts.

\section{- Principles of ethical processes}

1. Transparency: Researchers must be open with their goals, needs, constraints, and in particular the resources involved in a project (i.e. budgets, sources of funding) to all collaborators.

2. Accountability: Researchers must justify their decisions and actions to community partners, not making decisions unilaterally without consultation and keeping to agreements that have been made. Once a collaboration is established, accountability goes both ways, as researchers need also to feel that their input and agreements are respected and valued by partners.

3. Do No Harm: We know that while trying to actually "do good" by pursuing impactful engaged research we can inadvertently harm those we are seeking to support. We must think through the impacts of our work at every stage and avoid harmful impacts (reputational, financial, political) to the best of our ability.

4. Respecting alliances: When working with collaborative groups (like networks, alliances, coalitions), researchers must be careful to not pick off and work with individuals in a way that sidelines or subverts the group's decisions and values.

5. Respecting other knowledges and analyses: Since our goal is to build shared analysis, we must be open to and accepting of knowledges and analysis that are not our own and commit to taking these seriously even when our analysis differs.

6. A commitment to the long term and relationship-building: As much as possible, being "in it for the long haul" through building projects, authentic relationships, and power over time.

\section{- Principles of "resourcing"}

1. Remuneration of partners for time and expertise (honorariums) and providing for travel and other costs associated with the research process. 
2. Providing valuable work to partners (e.g., grant writing, research on requested topics, digging fence post holes on the farm, etc.): build capacity in all areas of expertise-in both research and partner communities - such that interdependence cultivates equity.

3. Strive to avoid competition with community partners in fundraising: seek funding from sources not available to community groups, leverage existing resources; include everyone in budgeting issues (beyond honorariums).

\section{- Principles involving data}

1. Interpretation should be dialogical, with the goal of reaching shared analysis.

2. Write-ups must be done with time and space for feedback from partners; stories should not be shared without permission; how data will be written up (by what process and timeline) should be discussed early on in research design. Wherever possible, co-authorship including community partners should be prioritized.

3. Dissemination should be planned to be broad (i.e., beyond academic circles), include (on at least equal footing) public audiences, and remain attentive to potential (negative) impacts (see "do no harm" principle). When the research is presented, partners will be fully credited for their integral role, and not merely cited as protagonists or supporters, as appropriate.

\section{- Work on institutions}

1. We know that this approach to research is still not widely accepted within academic and other institutions and can be more difficult to pursue. Therefore, we commit to using our positions within those institutions to move their internal values and support structures (e.g., funding, tenure decisions) toward this form of research.

2. Our ambitious and ultimate goal is to move from simply lowering disincentives to engaged research, to engendering systemic change in "research" as a whole!

3. We also want to acknowledge that academia and other research institutions are not homogeneous, and individuals within them vary in power and privilege, according to (among other factors) race, gender, class, and positional status. Because some of us have more precarious positions in our respective institutions, we invite the less precarious to leverage their privilege for their colleagues as well as community partners.

We recognize that some protocols (e.g., cocreating research questions) are aspirational, and may only be appropriate in certain circumstances, whereas the principles underlying them (e.g., accountability, transparency, sharing of resources, non-exploitative relationship building) are nonnegotiable. We expect good-faith efforts from ARC members to stay true to the principles and develop research processes in dialogue, with these guidelines shaping but not limiting what is possible and appropriate in every circumstance. We also recognize that many valid ways to do scholaractivism and engaged research exist. These principles, we hope, can be a starting point for other researchers and organizations with whom they collaborate to come to a shared understanding and expectation about the research process in their particular situations.

These Principles \& Protocols have associated benefits and challenges. On one hand, our individual experiences of negotiating accountable relationships with frontline organizations suggest that this practice facilitates a more robust method of coproducing knowledge, that is, of drawing on the different knowledges of researchers and frontline organizations to create a more accurate and ultimately effective way of knowing (Homsy \& Warner, 2013). Dialogue between different kinds of knowledge, or diálogo de saberes, moreover, is a key tenet of agroecology and has been central to the ability of La Via Campesina and other social movements to develop and advance agroecological 
understandings across diverse constituencies (Martínez-Torres \& Rosset, 2014).

On the other hand, developing the Principles $\&$ Protocols was really just a start. How would we hold ourselves accountable to them? What theoretical and practical contradictions might they embed? How could we overcome the real challenge that soon emerged for us: the near-impossibility of doing scholar-activism if it remained additive to the exigencies of the "real work" demanded by our professions? Most activist-scholars, including ARC's members, juggle heavy loads of research, teaching, mentorship, publishing, fundraising, NGO management, and university service responsibilities. As long as activist-scholar work comes atop everything else and is not part of scholars' recognized and rewarded proficiency, it represents an investment of time and resources antagonistic to sustaining our professional careers - to say nothing of our sanities. A way of nudging from competition to synergy is by finding manageable ways to center our professional lives more on scholar-activism.

In the next section, we share two ways that $\mathrm{ARC}$ is strengthening a community of practice in this respect. First is through mentoring and teaching, illustrated through the example of the farm bill practicum taught by one of our members at American University. Second is through working to change the incentive structures at institutions that inadequately recognize and reward scholar-activist research; such barriers put further strain on academics to choose between professional success and advancing social change.

\section{Integrating Accountability and Participatory Research in Education}

In "Breaking the Chains: How Activism can Help Change Teaching and Scholarship," George Lipsitz (2008) argues that intellectual work in contemporary public institutions is constricted "in debilitating ways" (p. 93). The privatization of higher education and ideological opposition among elites to the very idea of public learning, he suggests, "pressure teachers to privilege technical expertise over critical, contemplative, and creative thinking" (Lipsitz, 2008, p. 93). Ironically, academics facing a gauntlet of high-stakes testing, school-to-work programs, and efforts to transform universities into
$\mathrm{R} \& \mathrm{D}$ arms of the military and transnational corporations can find themselves "too busy, too pressured, too embroiled in activity to think much about their philosophy, ideology, or structure" (Lipsitz, 2008, p. 92). Grassroot movement organizers are no less squeezed, indeed seldom enjoying the privilege of a pause in struggles for survival. By the same token, these constraints make common cause between scholars and movements-suggesting that we have much to learn from one another: "In both activism and the academy, we suffer when we do not know enough, when critical reflection becomes too far removed from practical activity, and when the imperatives of our daily work leave too little opportunity for analysis, reflection, and critique" (Lipsitz, 2008, p. 93).

Teaching and mentoring are invaluable sites of scholar-activism within which participatory-action, decolonial, and agroecological approaches can be cultivated with our students. It makes little sense to ignore the spaces where many of us spend significant portions of our days, and to overlook the formative power of working with students. A growing literature on pedagogy for sustainable food systems points to the potential of community-based learning and community-partnered research courses for equipping students with the knowledge and skills they need to work with communities, NGOs, and frontline groups to catalyze structural change for racial justice and economic equity (Bradley, Gregory, Armstrong, Arthur, \& Porter, 2018; Swords, Frith, \& Lapp, 2018; Valley, Wittman, Jordan, Ahmed, \& Galt, 2018; Valley et al., 2020). Diverse models and designs exist for such courses. At the graduate level, if activistscholars can introduce and connect professional and doctoral students to projects that are movement-led and movement-requested, the resulting collaborations can bring the faculty members' mentoring and research roles more into alignment with activist objectives. Students can learn about the history and geography of science-movement research relationships and their tensions and challenges, which can provide insights to guide innovative doctoral dissertations and masters' theses, and potentially their community and professional work thereafter. Faculty can learn to create synergies between their routine responsibilities and 
community-based efforts, including through the courses they develop.

One example of such a course is the master's capstone farm bill practicum that Graddy-Lovelace teaches at American University (AU). This innovative course builds research collaborations between graduate students and community partners such as the Rural Coalition (RC) and National Family Farm Coalition (NFFC) and their member groups. These coalitions, composed of grassroots organizations like the Federation of Southern Cooperatives/Land Assistance Fund, National Latino Farmer \& Rancher Trade Association, and Oklahoma Black Historical Research Project, work for transformational change to U.S. agricultural policy in general, and the farm bill in particular. In the typical business or policy school model, students conduct professional projects for their "clients." In this practicum, by contrast, the learning is mutual, iterative, and nonlinear. While Graddy-Lovelace took the lead in proposing the concept to RC and NFFC leaders, the organizations recognized the potential for useful assistance that could improve their capacity to chronicle, contextualize, and articulate grassroots agrarian justice priorities to multiple audiences, including policy-makers. AU administrators expressed curiosity with the first farm bill practicum of 2013 and have supported the class since, although they describe it as "rural development" rather than agrarian justice. AU also provided a few thousand dollars to assist student travel across the U.S. to farm sites, cooperative hubs, and key farmer-led meetings. Graddy-Lovelace attempted to secure institutional funds to remunerate community partners for their time and energy in these collaborations; AU declined and suggested seeking external funds.

How does the practicum work? Graduate students apply to join; most applicants have already taken a semester-long "Political Ecologies of Food \& Agriculture" seminar on international agricultural policy debates. This course wrestles with dominant paradigms such as new Green Revolutions, feed-the-world white saviorism, and technocratic, agri-tech quick fixes. Students learn about the colonial origins of agriculture in the Americas, including Indigenous genocide and African enslavement. Students also absorb farm justice and farmworker justice movement histories, Black and Indigenous women-led agrarian resistance, and food sovereignty organizing from Fannie Lou Hamer to the Nyéléni Declaration. Some applicants do not take the course, but have relevant backgrounds in agri-food practices, sciences, businesses, or policy; all students pack in a lot of reading during the first month.

Only after this historical, interdisciplinary orientation do students meet with the community partners. Depending on partner needs, students develop projects ranging from policy briefs, GIS maps, and agricultural economic data analyses to documentary shorts, data visualizations, photo essays, and literature reviews. These activities are guided by significant preparatory work by GraddyLovelace, who, in line with the Principles \& Protocols, engages partners in ongoing dialogue, nurtures collaboration throughout the research process, and creates space for movement partners to readjust their needs as the process moves along. The CVs students submit in their course application help discern matches between their skills and interests and community needs; mutual interests are honed through dialogue and collective brainstorming into multiple, interconnected group projects. The ambitious goal is to design, implement, edit, and present research projects within the semester's tight timeline.

For example, students from the 2015 practicum traveled to Oklahoma to meet with and learn from Rural Coalition board member Willard Tillman, who cofounded and directs the Oklahoma Black Historical Research Project. Tillman and colleagues introduced students to the problems leading to-and emerging from-invasive red cedar across Oklahoma, including the disproportionate impact on Black farmers. Students from the 2017 practicum built on this foundation and returned to Oklahoma to continue gathering information. Working with Tillman and Rural Coalition leader Lorette Picciano, the students researched the issue through archival maps, USDA Environmental Quality Incentives Program (EQIP) secondary data synthesis, policy analysis, and academic literature review.

Another student team in the 2017 cohort traveled to Iowa to meet with longtime National Fam- 
ily Farm Coalition member Brad Wilson, who shared his extensive, nondigitized home archive of historical documents from the 1980s farm crisis and related farmer mobilizations. Again, this collaboration involved a community partner providing primary source information, and the student-alums working to contextualize it within secondary data, policy history, and social and political theory.

In the seven years of this practicum's life, we have begun to see benefits within and beyond the university. A key one is pedagogical. Students learn more about U.S. agricultural policy and politics through this experiential learning process than textbooks can reveal. They witness and are invited to participate in community organizing with legacies in Civil Rights, Black Power, indigenous, farm justice, and farm-labor movements. From AU's side, initial concerns that community partners lacked the professional heft of a World Bank client have mostly subsided, as alumni report drawing directly on the valuable skills and knowledge they gained in their future endeavors. Many now work in various agrarian justice organizations.

Community partners, in turn, have gained deliverables for their own research needs, outreach, and movement building (many posted on https://farmbillfairness.org). In a somewhat surprising turn, community partners have requested that promising policy briefs be expanded into formal scholarly publications. Complicating Derrickson and Routledge's (2015) resource mobilization hypothesis, rather than value AU partners for resources that could be directed to their own organizational sites and spaces, frontline groups emphasized dissemination in academic outlets. They wanted their policy-relevant analyses to be peerreviewed, published, and citable-potentially granting the work wider uptake and legitimacy than if buried in a shared folder, inbox, or obscure website. Still, the time-limited semester curtails time for fine-tuning and editing of projects. Often, at the final presentation, just as the masters students are about to graduate, community partners and the students will lament that the project has just gotten started.

Extending the collaborations into postpracticum space therefore has been another important outcome of the course. The practicum has become biannual to allow for ongoing work with alumni in the long peer-review and revision process. Alumni from 2016 and Graddy-Lovelace published an open access article on contemporary policy discrimination against Black farmers (Orozco, Ward, \& Graddy-Lovelace, 2018). Alumni from 2017 and Graddy-Lovelace co-authored a piece with movement leaders on the connections between USDA institutional racism in conservation policy and the invasive spread of red cedar on farming land in Oklahoma (Fagundes et al., 2019).

As COVID-19 exposes the injustices and vulnerabilities of the dominant U.S. agri-food system, the practicum becomes even more needed. Teaching it has shown that practical challenges persist in making synergies between academic responsibilities and community-based work: from toxic white tendencies to appropriate movement knowledge, to the transient semester. The practicum's demography (majority white) has not yet reflected the racial diversity of the frontline coalitions with which students are collaborating. High tuition and thus the potential for high debt likely discourage students of diverse backgrounds from applying to AU, contributing to its predominantly white composition. The course also needs to pull in new faculty expertise: community partners seek access to key skills beyond what Graddy-Lovelace can train her students in, such as statistical regression, advanced GIS, legal assistance, and marketing analysis. There remains an ongoing need to fairly remunerate lowresource farmers and movement leaders for their time and labor in mentoring students through these complex issues and struggles.

\section{Creating Institutional Space for Scholar- Activist Work}

Teaching and mentorship are ways to begin recentering the "side project" that ARC constitutes for many of us into a core professional competency. Especially as graduate students begin developing dissertation projects with movement partners and as faculty start building community-based courses, the roles of advising, research, teaching, and scholar-activism begin to more closely cohere. However, in order for this recentering to become feasible, deeper structural and institutional changes must occur. 
It is no secret. Powerful, entrenched institutional cultures at universities and colleges help discourage scholars, including those in ARC, from becoming scholar-activists. Evaluation, recognition, and reward in academic life usually proceed through relentlessly individual and individualizing processes, in tension with activism, which usually encourages more collaborative and social thinking (Lipsitz, 2008). Scholar-activists often find themselves torn between what Duncan et al. (2019) aptly characterize as "dual political commitments," as they are "accountable to two worlds with distinct principles, practices, modes of knowledge production (Juris \& Khasnabish, 2013), and modes of evaluation, regulation and measuring impact (Borras, 2016)" (Duncan et al., 2019, pp. 5-6).

In response, ARC is pooling and exchanging ideas, strategies, and successful examples so that members can begin pressing for change in their home institutions. A number of groups of scholars and organizations (e.g., the Association of American Colleges \& Universities) have produced valuable guidance that we can adapt to our values and situations. We have been examining opportunities for change that span university missions, academic cultures, reward structures, educational programs, aid to students, and logistical support for grassroot movements (Beaulieu, Breton, \& Brousselle, 2018). We outline five interlinked opportunities here.

\section{Remaking reward structures. Junior faculty} are often counseled to save their activism for after tenure. This advice, unfortunately, sets up for a two-pronged dilemma of sidelining younger, energetic faculty from scholar-activism and delegitimizing such work as unworthy of intellectual merit.

Toward shifting standards of legitimacy, faculty can advocate for revisions to tenure, promotion, merit review, and hiring policies. Junior faculty can defuse risk by organizing together and collectively demanding that their departments recognize the scientific value of collaborating with frontline groups in grants and research projects. Tenured faculty can support these efforts by making their revisions to existing departmental practices visible to everyone, not just review committees. For example, in their files for promotion, tenure, and merit reviews, faculty can publicly submit publications with movement members as co-authors as evidence of work that enhances the rigor of science, rather than diminishes it. Instead of relying only on academic papers and books, faculty-junior and tenured alike - can insist that proof of scholarship take diverse forms such as reports, workshops, opinion essays, broadcasts, websites, GIS maps, software, and presentations for policymakers.

Faculty can also demand a reconceptualization of who should benefit from research. They can prioritize publishing in open access journals and books, refuse patents and other forms of intellectual property on publicly funded research, and work on creative ways to connect research findings to policy changes and material support for community organizing. Just as important, faculty can build collaborative research communities. Academic resources are usually awarded on a competitive basis, pitting individuals against one another in a struggle for power, status, and funding. By contrast, researchers can choose to cooperatively pool their resources; this in turn can reduce the drain on community groups that occurs when "elite" researchers capture their time and energy and can give underrepresented minority students and precarious faculty, like lecturers, greater access to community-based projects.

Faculty can leverage "diversity" efforts underway at many universities, where, as part of promotion and merit reviews, faculty are asked to voluntarily prepare statements about their contributions to diversity. Faculty can push their departments to make such statements mandatory and can use this space to document how research with grassroot movements and the development of new community-based courses strengthens diversity while also enhancing their chances of getting a promotion or pay raise. Campus administrations can be pressed to award off-scale raises to recognize those who have made extraordinary contributions to diversity interests through their research, teaching, or service. Departments and schools can also reserve some of their research funds specifically for faculty who choose to collaborate with underrepresented communities.

2. Mobilizing campus resources. Depending on the particular institution, faculty can commit to 
using existing research support and educational resources toward advancing activist-scholarship. At the campus level, they can apply for teaching fellowships, research awards for junior professors, technology acquisition funds, or student union grants (e.g., for "greening the campus"). In some cases, universities have public service programs that offer small grants to help faculty develop or revise courses with a community-engagement element. Professional schools often require students to undertake team-based master's capstone projects or policy analysis exercises; these can be opportunities to propose community-based ideas around which students can coalesce. Those schoolsparticularly law schools - may have practical clinics whose members could be interested in working on a community-driven problem. Faculty can also draw on research apprenticeship and internship programs, if these exist, to incentivize undergraduate students to join their activist-scholar projects with frontline partners. Students can provide important research staffing under faculty supervision. At UC Berkeley, for example, the Sponsored Undergraduate Research and Undergraduate Research Apprentice programs provide academic credit and grants to students. However, a highly uneven distribution of wealth and resources exists across the university sector, and many institutions do not choose to invest in such educational opportunities. Faculty can agitate either for greater access to or to create such programs if they do not already exist.

\section{Supplying logistical support to movements.} Another way activist-scholars can support grassroots organizations is through providing material resources directly to movement partners. Faculty can learn how to route university and extramural funds toward community groups who wish to conduct or participate in research. Some researchers already make a point of including grassroot organizations in their grant applications as a testament to the "broader impacts" of their research, a criterion of funders such as the National Science Foundation. Activist-scholars can also provide access to library materials and electronic databases that are otherwise behind paywalls, secure classrooms and other spaces for meetings and events, and use personal and institutional connections to continually press for better resourcing (money, labor time, information) of vulnerable communities on whose lives quality participatory research - to say nothing of the health of society writ large-depends. By doing all these things and publicizing it to their colleagues, activist-scholars can make it "normal" practice in the university to provide logistical aid to grassroots partners.

4. Centering anti-oppression. Following mass protests against systemic racism and police violence sparked by the murder of George Floyd in spring 2020, many universities across the U.S. face mounting demands from students for anti-racist change. We are in a critical moment that has already provided openings for more activistscholarship. Students are calling for course content to be redesigned to integrate work by Black, Indigenous and people of color (BIPOC) scholars and to address the colonial origins of scientific knowledge-making. Graduates, undergraduates, and faculty are urging departments to hire BIPOC scholars, change mentoring guidelines to be more responsive to student needs, and value contributions to equity and diversity in promotion cases. Departments in multiple fields are contemplating incentivizing faculty to alter their authorship, citation practices, and research collaborations to include BIPOC and community voices. Importantly, too, students are asking for more teaching and research that reflects community priorities, such as the impacts of policing, food and housing insecurity, and reparations for land stolen from Indigenous peoples. As a result of these student demands, astute faculty now have more leverage to push for funding of community-based projects, fair remuneration of grassroots activists, and the other ideas we have outlined here.

Especially now, when universities face steep financial losses due to COVID-related fallout (declining enrollment, tuition fee discounts, the costs of switching to online teaching), their first instinct is to press forward an austerity regime. Staff, contingent faculty, and services are the first to be cut. But universities still have substantial resources that can be reallocated to alternative edu- 
cational and research models - and faculty can organize around this goal.

5. Reshaping academic cultures. A fundamental way that faculty can make more room for activistscholarship in their departments and professions is to show that their activities are very much "real work" - not additional or superfluous. This calls for reshaping the academic cultures that define universities. All of the foregoing actions can contribute toward the deep structural and cognitive changes that are needed. Faculty can engage their fellow department members in conversations about the value of including grassroot voices in research; they can demonstrate "viability" by garnering external grants to do community-based research; and they can draw skeptical peers into contributing to projects, thereby exposing them to different ways of knowing and observing the world. At landgrant universities, scholars can point to their institution's public interest mission to justify what they do. In so acting, faculty challenge standard, often colonial, frameworks and categories of inquiry (CLEAR, 2018; Mignolo \& Escobar, 2013; Rappaport, 2008). They widen who is defined as "expert" and which forms of knowledge are granted authority and legitimacy (Anderson, Maughan, \& Pimbert, 2019). They implicitly affirm that all "scholarly" knowledge is not our own: we simply organize, filter, and renew knowledge that communities and activists already have. This holds true, moreover, across domains of science. Though agitating for institutional change has typically been the realm of social scientists, STEM colleagues must be encouraged and invited to join. Biophysical scientists, especially, contend with signals from colleagues that they are transgressing their disciplinary norms by engaging with frontline and grassroots groups - they are stigmatized as not being "scientific."

\section{Conclusions}

In this reflective essay, we have addressed a gap that persists between the desire for effective research on food systems change and the oftenfrustrating experience many grassroots organizations have with researchers. Systematizing the kinds of ethical processes that can lead to a genu- ine, accountable research partnership is one way to bridge it. By using these Principles \& Protocols (or many of the excellent existing community MOUs) as starting points for discussion, food systems researchers may be able to form more effective partnerships that result in both better science and more direct impact on transitions to sustainable food systems.

ARC is part of, and has learned from, a long, vibrant tradition of PAR and agroecology scholarship. What distinguishes our efforts is our attempt to go beyond individually negotiated MOUs for community-based research to develop operating mechanisms to support our work both individually and collectively. We thus adopted the Principles \& Protocols in late 2017. Given food systems scholars' drive to have research more directly effect social change, we hope that these principles can show one path forward. While they are clearly not the only way, we hope that what we have developed may be of use to scholars committed to navigating relationships of accountability, reciprocity, humility, and solidarity with the communities they work with. Beyond our expectations, we have been inspired to see how the Principles \& Protocols have traveled. In one case, a group of bioethicists involved in gene editing debates found these guidelines to be illuminating for their own work. In another case, we learned that a community organization had turned down a partnership with a research group because the scientists' principles for engagement were not up to par.

Of course, much work remains to implement the Principles \& Protocols in projects and everyday scholarly practice. Many tensions exist within ARC regarding how to translate its ethos into the oftenfraught conditions of collaborating with grassroots organizations. ARC members continually wrestle with the problems of navigating institutions and disciplinary norms and practices that deter movement-oriented scholarship. These tensions will not be easily resolved, if at all. Yet, achieving institutional change can help alleviate many of these tensions. ARC's strength lies in its diversity, in terms of geographies, disciplines, institutions, community relations, and individual histories that draw us to this work. By gathering a memberships of over 50 )and growing), ARC can mobilize its collective 
resources to help press forward agroecology transitions in North America. Being so dispersed presents major challenges-yet gives us something catalytic when it comes together.

\section{Acknowledgments}

We are grateful to Josh Sbicca and Tomás Madrigal for suggestions that sharpened the analysis in this paper, and to Chris Bacon and other Agroecology Research-Action Collective (ARC) members who were instrumental in drafting the principles.

Responsibility for errors, omissions, and the inevitable shortcomings of course belong to the authors alone. Kathy Ozer (National Family Farm Coalition), Lorette Picciano (Rural Coalition), Carlos Marentes and Andrianna Natsoulas (La Via Campesina), Saulo Araujo (WhyHunger), Shiney Varghese (IATP), and Marcia Ishii (PANNA) have provided invaluable solidarity as we work to "get our house in order." The farm bill practicum would not have been possible without the support of
Rudy Arredondo (National Latino Farmer Rancher Trade Association), Ben Burkett (Federation of Southern Cooperatives/Land Assistance Fund), and Willard Tillman (Oklahoma Black Historical Research Project, Inc). Thanks deeply to all members of the Agroecology Research-Action Collective who have shown us what it means to be greater than the sum of our parts.

\section{Land Acknowledgment}

The Awaswas-speaking Uypi Tribe, on whose unceded territory the University of California Santa Cruz was built; the Miami, Delaware, Potawatomi, and Shawnee people, on whose ancestral homelands and resources Indiana University was built; the Chochenyo speaking Ohlone people, on whose ancestral and unceded land UC Berkeley sits; the Piscataway and Nacotchtank-Anacostan people, on whose territories and waterways American University was built.

\section{References}

Agroecology Research-Action Collective. (2019). Our principles and protocols: How and on whose behalf we work. Retrieved from http://agroecologyresearchaction.org/principles-and-protocols/

Anderson, C. R., Bruil, J., Chappell, M. J., Kiss, C., \& Pimbert, M. P. (2019). From transition to domains of transformation: Getting to sustainable and just food systems through agroecology. Sustainability, 11(19), 5272. https://doi.org/10.3390/su11195272

Anderson, C. R., Maughan, C., \& Pimbert, M. P. (2018). Transformative agroecology learning in Europe: Building consciousness, skills and collective capacity for food sovereignty. Agriculture and Human Values, 36(3), 531-547. https://doi.org/10.1007/s10460-018-9894-0

Anderson, M. D. (2013). Beyond food security to realizing food rights in the US. Journal of Rural Studies, 29, 113-122. https://doi.org/10.1016/j.jrurstud.2012.09.004

Beaulieu, M., Breton, M., \& Brousselle, A. (2018). Conceptualizing 20 years of engaged scholarship: A scoping review. PLoS ONE, 13(2), e0193201. https://doi.org/10.1371/journal.pone.0193201

Bezner Kerr, R., Hickey, C., Lupafya, E., \& Dakishoni, L. (2019). Repairing rifts or reproducing inequalities? Agroecology, food sovereignty, and gender justice in Malawi. The Journal of Peasant Studies, 46(7), 1499-1518. https://doi.org/10.1080/03066150.2018.1547897

Borras, Jr., S. M. (2016, April 14). Land politics, agrarian movements and scholar-activism [Video and transcript]. Inaugural Lecture at the International Institute of Social Studies. Retrieved from https://www.tni.org/en/publication/land-politics-agrarian-movements-and-scholar-activism

Bradley, K., Gregory, M. M., Armstrong, J., Arthur, M. L., \& Porter, C. M. (2018). Graduate students bringing emotional rigor to the heart of community-university relations in food dignity. Journal of Agriculture, Food Systems, and Community Development, 8(A), 221-236. https://doi.org/10.5304/jafscd.2018.08A.003.

Bradley, K., \& Herrera, H. (2016). Decolonizing food justice: Naming, resisting, and researching colonizing forces in the movement. Antipode, 48(1), 97-114. https://doi.org/10.1111/anti.12165

Brem-Wilson, J. (2014). From 'here' to 'there': Social movements, the academy and solidarity research. Socialist Studies/Études Socialistes, 10(1). https://doi.org/10.18740/S47P4F 
Brescia, S. (Ed.). (2017). Fertile ground: Scaling agroecology from the ground up. Oakland, CA: Food First Books.

Cabral, A. (1966, January). The weapon of theory. Address delivered to the first Tricontinental Conference of the Peoples of Asia, Africa and Latin America in Havana, Cuba.

Calhoun, C. (2008). Foreword. In C. R. Hale (Ed.), Engaging contradictions: Theory, politics, and methods of activist scholarship (pp. xiii-xxvi). Berkeley: University of California Press.

Chappell, M. J. (2018). Beginning to end hunger: Food and the environment in Belo Horizonte, Brazil, and beyond. Berkeley: University of California Press. https://doi.org/10.1525/9780520966338

Civic Laboratory for Environmental Action Research [CLEAR]. (2018). Civic laboratory for environmental action research (CLEAR) lab book: A living manual of our values, guidelines, and protocols. Department of Geography, Memorial University of Newfoundland. Retrieved from https://civiclaboratory.nl/clear-lab-book/

Croog, R., Hayes-Conroy, A., Guttierez-Velez, V. H., \& Saenz-Montoya, A. (2018). Real world food justice and the enigma of the scholar-activist label: A reflection on research values. ACME: An International Journal for Critical Geographies, 17(4). Retrieved from https://acme-journal.org/index.php/acme/article/view/1512

de Molina, M. G., Petersen, P. F., Peña, F. G., \& Capor, F. R. (2019). Political agroecology: Advancing the transition to sustainable food systems. New York: CRC Press. https://doi.org/10.1201/9780429428821

Derickson, K. D., \& Routledge, P. (2015). Resourcing scholar-activism: Collaboration, transformation, and the production of knowledge. The Professional Geographer, 67(1), 1-7. https://doi.org/10.1080/00330124.2014.883958

Duncan, J., Claeys, P., Rivera-Ferre, M. G., Oteros-Rozas, E., Van Dyck, B., Plank, C., \& Desmarais, A. A. (2019). Scholar-activists in an expanding European food sovereignty movement. The Journal of Peasant Studies. https://doi.org/10.1080/03066150.2019.1675646

Fagundes, C., Picciano, L., Tillman, W., Mleczko, J., Schwier, S., Graddy-Lovelace, G., Hall, F., \& Watson, T. (2019). Ecological costs of discrimination: Racism, red cedar and resilience in farm bill conservation policy in Oklahoma. Renewable Agriculture and Food Systems, 35(4), 420-434. https://doi.org/10.1017/S1742170519000322

Fals-Borda, O., \& Rahman, M. A. (Eds.). (1991). Action and knowledge: Breaking the monopoly with participatory action research. Bogotá: CINEP. https://doi.org/10.3362/9781780444239

Ferguson, R. (2019, December 9). Pesticides, heat, and the people who feed us: Climate change is making farmworkers' dangerous job even worse [Blog post]. Retrieved from Union of Concerned Scientists website: https://blog.ucsusa.org/rafter-ferguson/pesticides-heat-farmworkers

Gilmore, R. W. (1993). Public enemies and private intellectuals: Apartheid USA. Race \& Class, 35(1), 69-78. https://doi.org/10.1177/030639689303500107

Giraldo, O. F., \& Rosset, P. M. (2017). Agroecology as a territory in dispute: Between institutionality and social movements. The Journal of Peasant Studies, 45(3), 545-564. https://doi.org/10.1080/03066150.2017.1353496

Gliessman, S. (2017). Agroecology and food system change: A case study of strawberries in California. In S. Brescia (Ed.), Fertile ground: Scaling agroecology from the ground up (pp. 87-103). Oakland, CA: Food First Books. Retrieved from https:// foodfirst.org/fertile-ground-scaling-agroecology-from-the-ground-up/

Graddy-Lovelace, G. (2017). The coloniality of US agricultural policy: Articulating agrarian (in)justice. The Journal of Peasant Studies, 44(1), 78-99. https://doi.org/10.1080/03066150.2016.1192133

Gwiszcz, J. (2016). Practicing ethical activist scholarship for sustainability. Brighton, UK: STEPS Centre.

Hale, C. R. (2008). Engaging contradictions: Theory, politics, and methods of activist scholarship. Berkeley: University of California Press.

Hall, B. L., \& Kidd, J. R. (Eds.). (1978). Adult learning: A design for action. Oxford: Permagon.

Herrera, H. (2018). The value and meaning of experience in food system learning spaces: Reflections from the activist and traditional community perspectives. ACME: An International Journal for Critical Geographies, 17(4). Retrieved from https://acme-journal.org/index.php/acme/article/view/1513

Holt-Giménez, E. (2006). Campesino a campesino: Voices from Latin America's farmer to farmer movement for sustainable agriculture. Oakland, CA: Food First Books.

Homsy, G. C., \& Warner, M. E. (2013). Climate change and the co-production of knowledge and policy in rural USA communities. Sociologia Ruralis, 53(3), 291-310. https://doi.org/10.1111/soru.12013 
Hudson, M., Garrison, N.'A., Sterling, R., Caron, N. R., Fox, K., Yracheta, J., .. Carroll, S. R. (2020). Rights, interests and expectations: Indigenous perspectives on unrestricted access to genomic data. Nature Reviews Genetics, 21, 377384. https://doi.org/10.1038/s41576-020-0228-x

Iles, A., Graddy-Lovelace, G., Montenegro de Wit, M., \& Galt, R. (2016). Agricultural systems: Co-producing knowledge and food. In U. Felt, R. Fouché, C. Miller, \& L. Smith-Doerr (Eds.), The handbook of science and technology studies, 4th edition (pp. 943-972). Cambridge, MA: MIT Press.

International Planning Committee for Food Sovereignty. (2015). Declaration of the international forum for agroecology: Nyéléni, Mali. Retrieved from http://www.foodsovereignty.org/wp-content/uploads/2015/02/Download-declarationAgroecology-Nyeleni-2015.pdf

Ishii-Eiteman, M. (2019, December 12). Global groundswell for agroecology [Blog post]. Retrieved from Pesticide Action Network North America website: https://www.panna.org/blog/global-groundswell-agroecology

Karuk-UC Berkeley Collaborative. (n.d.). Practicing Píkyav. Retrieved 2019 from https://nature.berkeley.edu/karuk-collaborative/?page $\mathrm{id}=165$

Levkoe C. Z., McClintock, N., Minkoff-Zern, L.-A., Coplen, A. K., Gaddis, J., Lo, J., ... Weiler, A. M. (2016). Forging links between food chain labor activists and academics. Journal of Agriculture, Food Systems, and Community Development, 6(2), 129-142. https://doi.org/10.5304/jafscd.2016.062.009

Lipsitz, G. (2008). Breaking the chains and steering the ship: How activism can help change teaching and scholarship. In C. R. Hale (Ed.), Engaging contradictions: Theory, politics, and methods of activist scholarship (pp. 88-112). Berkeley: University of California Press.

Madrigal, T. A. (2015). Agribusiness and Mexican farm worker families in Washington State (1964-2013): The emergence of the Pacific Rim capitalist market circuit (Unpublished doctoral dissertation), University of California Santa Barbara.

Martínez-Torres, M. E. \& Rosset P. M. (2014). Diálogo de saberes in La Vía Campesina: Food sovereignty and agroecology. The Journal of Peasant Studies, 41(6), 979-997. https://doi.org/10.1080/03066150.2013.872632

McCune, N. \& Sánchez, M. (2019). Teaching the territory: Agroecological pedagogy and popular movements. Agriculture and Human V alues, 36(3), 595-610. https://doi.org/10.1007/s10460-018-9853-9

Meek, D. (2020). The political ecology of education: Brazil's Landless Workers' Movement and the politics of knowledge. Morgantown: West Virginia University Press. Méndez, V. E., Bacon, C. M., Cohen, R., \& Gliessman, S. R. (Eds.). (2015). Agroecology: A transdisciplinary, participatory and action-oriented approach. Boca Raton, FL: CRC Press. https://doi.org/10.1201/b19500

Mier y Terán Giménez Cacho, M., Giraldo, O. F., Aldasoro, M., Morales, H., Ferguson, B. G., Rosset, P., Khadse, A., \& Campos, C. (2018). Bringing agroecology to scale: Key drivers and emblematic cases. Agroecology and Sustainable Food Systems, 42(6), 637-665. https://doi.org/10.1080/21683565.2018.1443313

Mignolo, W. D., \& Escobar, A. (Eds.) (2013). Globalization and the decolonial option. London: Routledge. https://doi.org/10.4324/9781315868448

Montenegro de Wit, M. (2014). A lighthouse for urban agriculture: University, community, and redefining expertise in the food system. Gastronomica: The Journal for Food Studies, 14(1), 9-22. https://doi.org/10.1525/gfc.2014.14.1.9

Orozco, A. A., Ward, A., \& Graddy-Lovelace, G. (2018). Documenting USDA discrimination: Community-partnered research on farm policy for land justice. ACME: An International Journal for Critical Geographies, 17(4), 999-1023. https://acme-journal.org/index.php/acme/article/view/1514

Patel, R. (2009). Food sovereignty. The Journal of Peasant Studies, 36(3), 663-706. https://doi.org/10.1080/03066150903143079

Porter, C. M. (2018). Fostering formal learning in the food dignity project. Journal of Agriculture, Food Systems, and Community Development, 8(A), 213-219. https://doi.org/10.5304/jafscd.2018.08A.016

Pulido, L. (2008). FAQs: Frequently (un)asked questions about being a scholar activist. In C. R. Hale (Ed.), Engaging contradictions: Theory, politics, and methods of activist scholarship (pp. 341-366). Berkeley: University of California Press.

Rappaport, J. (2008). Beyond participant observation: Collaborative ethnography as theoretical innovation. Collaborative Anthropologies, 1(1), 1-31. https://doi.org/10.1353/cla.0.0014 
Reynolds, K., Block, D., \& Bradley, K. (2018). Food justice scholar-activism and activist-scholarship: Working beyond dichotomies to deepen social justice praxis. ACME: An International Journal for Critical Geographies, 17(4). Retrieved from https://acme-journal.org/index.php/acme/article/view/1735

Rosset, P. M. \& Altieri, M.A. (2017). Agroecology: Science and politics. Halifax: Fernwood Publishing. https://doi.org/10.3362/9781780449944

Sbicca, J. (2018). Food justice now! Deepening the roots of social struggle. Minneapolis: University of Minnesota Press. https://doi.org/10.5749/j.ctv3dnnrt

Shattuck, A., Schiavoni, C., \& VanGelder, Z. (Eds.) (2018). The politics of food sovereignty: Concept, practice and social movements. London: Routledge.

Swords, A., Frith, A., \& Lapp, J. (2018). Community-campus collaborations for food justice: Strategy, successes and challenges at a teaching-focused college. Journal of Agriculture, Food Systems, and Community Development, 8(Suppl. 1), 261-277. https://doi.org/10.5304/jafscd.2018.08A.009

Tarlau, R. (2019). Occupying schools, occupying land: How the Landless Workers' Movement transformed Brazilian education. Oxford, UK: Oxford University Press. https://doi.org/10.1093/oso/9780190870324.001.0001

Tuck, E., \& Yang, K. W. (2012). Decolonization is not a metaphor. Decolonization: Indigeneity, Education \& Society, 1(1), 140. Retrieved from https://www.ryerson.ca/content/dam/aec/pdfs/Decolonization-is-not-a-metaphor.pdf

Valley, W., Anderson, M., Blackstone, N. T., Sterling, E., Betley, E., Akabas, S., ... Spiller, K. (2020). Towards an equity competency model for sustainable food systems education programs. Elementa: Science of the Anthropocene, 8(33). https://doi.org/10.1525/elementa.428

Valley, W., Wittman, H., Jordan, N., Ahmed, S., \& Galt, R. (2018). An emerging signature pedagogy for sustainable food systems education. Renewable Agriculture and Food Systems, 33(5), 467-480. https://doi.org/10.1017/S1742170517000199

van den Berg, L., Kieft, H., \& Meekma, A. (2017). Closed-loop farming and cooperative innovation in the Netherlands' Northern Frisian woodlands In S. Brescia (Ed.), Fertile ground: scaling agroecology from the ground up (pp. 171-182). Oakland, CA: Food First Books.

Vandermeer, J., \& Perfecto, I. (2013). Complex traditions: Intersecting theoretical frameworks in agroecological research. Agroecology and Sustainable Food Systems, 37(1), 76-89. https://doi.org/10.1080/10440046.2012.717904

Varghese, S. (2020, April 2). IATP comment on the zero draft of the CFS policy recommendation on 'Agroecological and other innovative approaches for sustainable food systems that ensure food security and nutrition.' Institute for Agriculture and Trade Policy. Retrieved from https://www.iatp.org/documents/letter-un-committee-food-security-agroecological-and-other-innovative-approaches

Wakeford, T., \& Sanchez Rodriguez, J. (2018). Participatory action research: Towards a more fruitful knowledge. In K. Facer \& K. Dunleavy (Eds.), Connected communities foundation series. Bristol: University of Bristol/AHRC Connected Communities Programme.

Wills, C., \& Sampson, D. (2018). Delicious revolution [Podcast]. Retrieved from https://podcasts.apple.com/us/podcast/delicious-revolution/id1059065641

Wittman, H., \& Blesh, J. (2017). Food sovereignty and Fome Zero: Connecting public food procurement programmes to sustainable rural development in Brazil. Journal of Agrarian Change, 17(1), 81-105. https://doi.org/10.1111/joac.12131 